\title{
Determinants of postabsorptive endogenous glucose output in non-diabetic subjects
}

\author{
A. Natali, E. Toschi, S. Camastra, A. Gastaldelli, L. Groop, E. Ferrannini, on behalf of the European Group \\ for the Study of Insulin Resistance (EGIR)*
}

\section{Abstract}

Aim/hypothesis. To gain insight into the physiologic determinants of postabsorptive endogenous glucose output (EGO) in humans.

Methods. We analysed the data of 344 non-diabetic subjects (212 men and 132 women) with a wide range of age (18-85 years) and body mass index (15-55 $\mathrm{kg} / \mathrm{m}^{2}$ ) who participated in the European Group for the Study of Insulin Resistance (EGIR) project. Whole-body endogenous glucose output was measured by tracer $\left(\left[{ }^{3} \mathrm{H}\right]\right.$ glucose $)$ dilution at steady-state, peripheral insulin sensitivity $(\partial$ glucose clearance/ $\partial$ insulin) was measured by the euglycaemic insulin (7 pmol $\times \min ^{-1} \times \mathrm{kg}^{-1}$ ) clamp technique.

Results. Whole-body endogenous glucose output showed a large variability (mean $=768 \pm 202 \mu \mathrm{mol}$. $\mathrm{min}^{-1}$, range 209-1512) and was strongly related to lean body mass $(r=0.63, p<0.0001)$. This association entirely explained the endogenous glucose output being higher in men than in women $(827 \pm 189$ vs $\left.674 \times 187 \mu \mathrm{mol} \times \min ^{-1}, p<0.0001\right)$, its relation to body mass $(+10 \pm 2$ per unit of body mass index, $p<0.0001)$ and its trend to decline with age $(-1.1 \pm$ $0.7 \mu \mathrm{mol} \cdot \mathrm{min}^{-1}$ per year, $\left.p=0.10\right)$. Although inversely related to one another $(r=-0.41, p<0.0001)$, peripheral insulin sensitivity and fasting plasma insulin were both independently associated with endogenous glucose output in an inverse fashion (with partial $r$ 's of 0.19 and 0.21 , respectively, after adjusting for lean body mass and centre, $p<0.0001$ for both).

Conclusion/interpretation. Among non-diabetic subjects in the postabsorptive condition, total body endogenous glucose output variability is wide and is largely explained by the amount of lean mass; this, in turn, explains differences in total endogenous glucose output due to sex, obesity and age. Independently of the amount of lean mass, peripheral insulin resistance is associated with a higher endogenous glucose output independently of fasting plasma insulin concentration, suggesting coupled regulation of insulin action in peripheral tissues and the liver. [Diabetologia (2000) 43: 1266-1272]

Keywords Endogenous glucose production, insulin resistance, insulin.
Received: 26 April 2000 and in revised form: 3 July 2000

Corresponding author: A. Natali MD, CNR Institute of Clinical Physiology, Via Savi, 8, 56126 Pisa, Italy

Abbreviations: EGO, endogenous glucose output; LBM, lean body mass; FGIR, European Group for the Study of Insulin Resistance; WHR, waist-to-hip circumference ratio; M value, insulin-stimulated glucose disposal; IS, peripheral insulin sensitivity; FPI, fasting plasma insulin concentrations; dpm, disintegrations per min.

\section{Introduction}

In non-diabetic subjects, fasting plasma glucose concentrations are maintained stable through a fine balance between glucose utilisation by body tissues and endogenous glucose release. Different laboratories [1-4] have reported (mostly in small groups of subjects) that, in euglycaemic subjects after an overnight fast endogenous glucose utilisation averages 9-12 $\mu \mathrm{mol} \cdot \mathrm{min}^{-1}$ per $\mathrm{kg}$ of body weight, with a rather limited inter-individual variability (20-30\%). In a $75-\mathrm{kg}$ man, therefore, approximately $9 \mathrm{~g}$ of glucose 
must be released into the circulation every hour to maintain euglycaemia. As shown by studies in experimental animals and in man, post absorbtive glucose production (sustained by the liver and to a lesser extent by the kidneys [5]) is regulated by plasma glucose concentration itself [4] insulin and counterregulatory hormones (mainly glucagon and adrenaline) [6]. Case control studies have shown that in the postabsorptive state diabetic patients in poor metabolic control [2] and severely stressed people [7] have an increased rate of endogenous glucose output (EGO), which is almost invariably associated with a reduced plasma glucose clearance and, therefore, hyperglycaemia. Due to the technical difficulty of using tracers in large groups of subjects, the physiologic determinants, the normal values and the true degree of inter-individual variability of postabsorptive EGO have, however, not been determined. Thus, whether age or sex affect postabsorptive EGO has not been established. Even more importantly, the effect of body size on EGO has not been described clearly; the definition of normalcy depends largely on how this flux is expressed (whole-body, per square metre, per kg of body weight or lean body mass (LBM) or liver and kidney mass). That different methods are adopted by different laboratories probably reflects the underlying uncertainty about the site of the main physiologic control; i. e. whether it is exerted on the production (liver and kidney) or utilisation process. If EGO is geared to match glucose utilisation, then the determinants of basal glucose uptake would also control EGO. In particular, whether there is a role for plasma insulin or insulin sensitivity or the respiratory quotient. These questions prompted us to analyse the data of 344 euglycaemic subjects (part of a large multicentre European data pooling project [8]) in whom both EGO (by tracer methodology) and insulin sensitivity (by the euglycaemic insulin clamp technique) were measured.

\section{Materials and methods}

Subjects. Among the 20 European Centres participating in the EGIR clamp data pooling project, 6 centres ( 3 in Italy, 2 in Finland and 1 in Denmark) also provided measurements of EGO in the postabsorptive state using the tracer dilution technique. A total of 354 subjects (132 women and 212 men) were included, each centre contributing at least 40 subjects; 8 subjects from one centre having an EGO 2.5 SD above the mean of the entire study group were considered outliers and excluded from the present analysis. Study subjects were selected at each centre according to the following criteria: (1) no clinical or laboratory evidence of cardiac, renal, liver or endocrine disease, (2) fasting plasma glucose concentration less than $6.7 \mathrm{mmol} \cdot \mathrm{l}^{-1}$ and normal glucose tolerance by the World Health Organisation (WHO) criteria, (3) arterial blood pressure lower than $160 / 95 \mathrm{~mm} \mathrm{Hg}$, (4) no recent (last 3 months) significant change ( $\geq 5 \%$ ) in body weight and (5) no current medication. At each centre, the protocol was reviewed and approved by the local ethics committee.
Protocol. For each subject the following variables were measured: age, height, weight, fasting and steady-state (= final 40 min of a 2-h clamp, see below) plasma glucose and insulin concentration. Body mass index was calculated as the weight (in $\mathrm{kg}$ ) divided by height $\left(\mathrm{cm}^{2}\right)$. Waist-to-hip circumference ratio (WHR) was calculated in only a subset of 102 subjects and done by measuring the waist circumference at the narrowest part of the torso and the hip circumference in a horizontal plane at the level of the maximum extension of the buttocks. Lean body mass (LBM) was estimated with the use of Hume's formula [9]. The accuracy of this estimate was evaluated in a subgroup of 91 subjects in whom LBM was also directly measured by the use of tritiated water $(n=33)$ or electrical bioimpedance $(n=58)$. In this subgroup, the agreement between these measures and Hume's formula, as estimated by simple regression analysis with no intercept, yielded $r$ values of 0.85 and 0.86 , for tritiated water and electrical bioimpedance, respectively ( $p<0.0001$ for both).

Whole-body EGO $\left(\mu \mathrm{mol} \cdot \mathrm{min}^{-1}\right)$ was measured between 1000 and 1100 hours (approximately 13-15 h after the last meal) according to the principle of tracer dilution at steady state. Briefly, a primed-continuous infusion of tritiated glucose $\left(3-{ }^{3} \mathrm{H}\right.$-glucose) was started and continued for $2 \mathrm{~h}$ (equilibration period). During the last $20 \mathrm{~min}$ of the equilibration period, three blood samples were obtained for the measurement of plasma tracer concentration. Postabsorptive glucose clearance $\left(\mathrm{GCL}=\mathrm{ml} \cdot \mathrm{min}^{-1}\right)$ was measured as the ratio between the constant tracer infusion rate [disintegrations per min $\left.(\mathrm{dpm}) \cdot \mathrm{min}^{-1}\right]$ and the plasma tracer concentration at steady state $\left(\mathrm{G}^{*}=\mathrm{dpm} \cdot \mathrm{ml}^{-1}\right)$. Whole-body EGO was thus calculated by multiplying plasma glucose concentration $\left(\mathrm{G}=\mu \mathrm{mol} \cdot \mathrm{ml}^{-1}\right)$ by GCL.

Endogenous glucose output during the clamp was measured assuming a monocompartment model for glucose kinetics. Insulin action was measured by the euglycaemic insulin clamp technique [10] using a primed insulin infusion rate of $1 \mathrm{mU} \cdot \mathrm{min}^{-1} \cdot \mathrm{kg}^{-1}$. An exogenous infusion of glucose $(20 \%$ solution) was started 4 min into the insulin infusion and adjusted every 5-10 min to maintain plasma glucose within about $10 \%$ of its baseline value. Three blood samples for the measurement of steady-state plasma glucose and insulin concentrations were obtained at 20-min intervals in the basal state and during the last $40 \mathrm{~min}$ of the clamp. Insulin-stimulated glucose disposal ( $M$ value) was calculated as the mean exogenous glucose infusion rate during the last $40 \mathrm{~min}$ of the clamp corrected for changes in glucose concentration within a distribution volume of $250 \mathrm{ml}$ per $\mathrm{kg}$ of body weight. Glucose clearance during the clamp was calculated as the ratio of glucose turnover ( $\mathrm{M}$ value plus EGO during the last 40 min of the clamp) to the mean glucose concentration of the last $40 \mathrm{~min}$ of the clamp. Peripheral insulin sensitivity (IS) was estimated as the difference between postabsorptive and insulin-stimulated plasma glucose clearance divided by the difference between clamp and postabsorptive plasma insulin concentrations $(\times 100)$. In a subgroup of 223 subjects, oxygen consumption and carbon dioxide production were measured by means of indirect calorimetry [11]. Concentrations of fasting plasma non-esterified fatty acids (NEFA) were measured in a subgroup of 245 subjects.

Analytical procedures. Plasma glucose was measured by the glucose oxidase method. Plasma insulin concentrations were measured by radioimmunoassay. Tritiated glucose concentration in plasma samples and infusates was measured after deproteinisation according to the Somogyl technique. Plasma concentrations of NEFA were measured spectrophotometrically. 


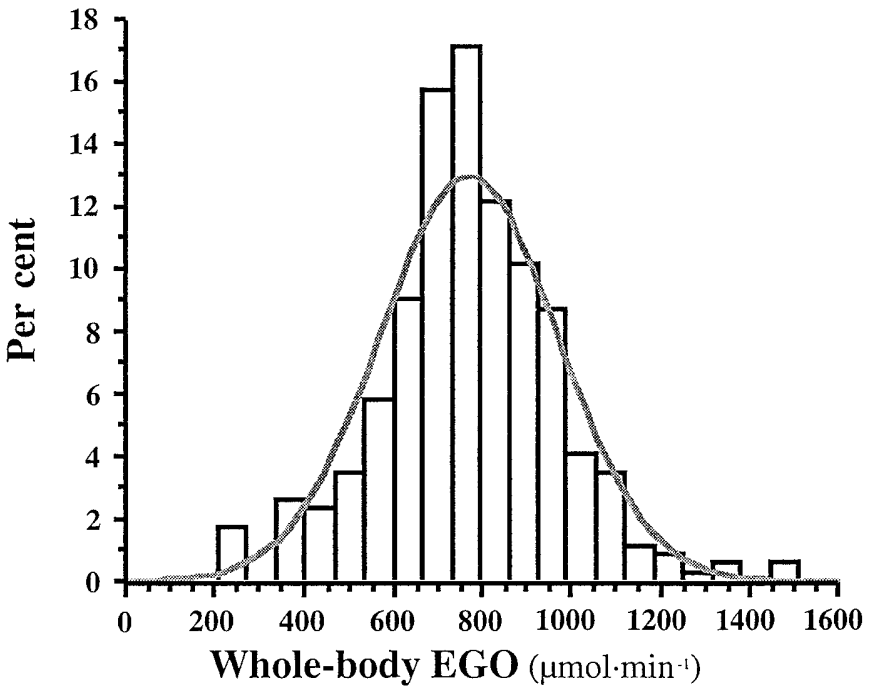

Fig. 1. Frequency distribution histogram of whole-body endogenous glucose output (EGO) in 344 non-diabetic subjects. The curve represents the theoretic profile of normal distribution ( $p=0.04$ by Shapiro-Wilk W test for normality of distribution)

Data analysis. Data are given as median and interquartile range. Plasma insulin and IS values showed a skewed distribution and were therefore logarithmically transformed for use in statistical analysis. Frequency distribution was considered normal if the Shapiro-Wilk W test yielded a $p$ value higher than 0.05 . Five dummy variables were introduced to account for between-centre differences in all multivariate regression models. Two-way ANOVA, simple and multiple regression analysis were carried out by standard techniques.

\section{Results}

The study cohort, which comprised only non-diabetic and otherwise healthy subjects over a range of age and BMI, also had a wide range of indices of glucose homeostasis. Whole-body EGO (Fig. 1) ranged from 209 to $1512 \mu \mathrm{mol} \cdot \mathrm{min}^{-1}$, with a $26 \%$ coefficient of variation and a quasi-normal distribution $(p=0.04$ by Shapiro-Wilk W test). Whole-body EGO was $23 \%$ higher in men than in women $(827 \pm 189$ vs $674 \pm 187 \mu \mathrm{mol} \cdot \mathrm{min}^{-1}, p<0.0001$ by unpaired $t$ test $)$ and was positively correlated with indices of body size in either sex (Fig. 2); the degree of association was slightly stronger with LBM than body weight or body surface area (the correlation coefficients for both sexes combined being 0.63 vs 0.54 and 0.59 , respectively). When LBM, body weight and body surface area were simultaneously entered into a multivariate regression model LBM was the only statistically significant predictor of whole-body EGO (partial $r$ s of $0.19,-0.007$ and -0.003 , respectively). The dependence of EGO on LBM was present in the data from all six centres, with correlation coefficients ranging from 0.69 to 0.54 and regression coefficient

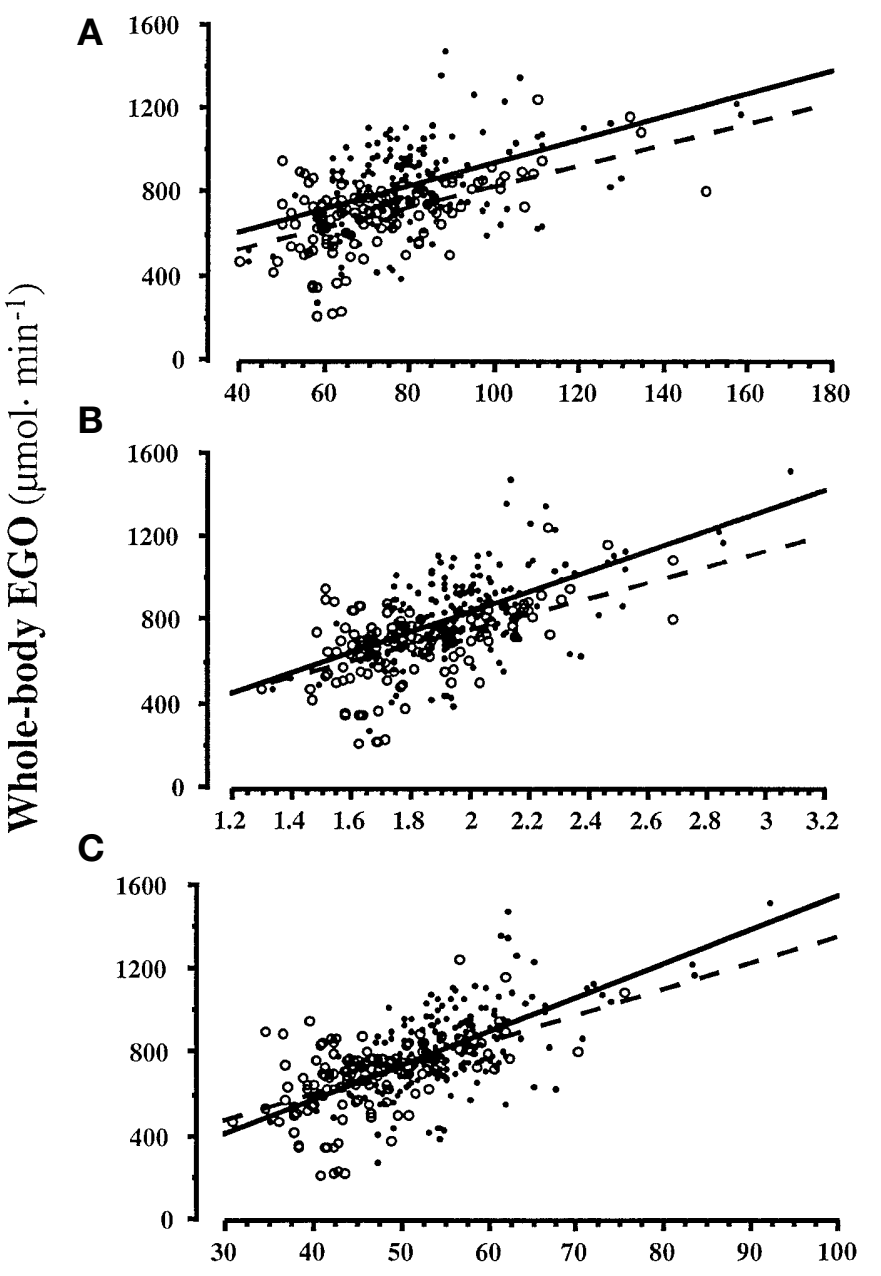

Fig. 2 A-C. Scatterplots of whole-body endogenous glucose output and three different indices of body mass. Male (O) and female $(\bigcirc)$ regression lines are indicated by continuous and dashed lines, respectively. A Weight (kg); $r=0.49$ (men), $r=0.49$ (women). B Body surface area $\left(\mathrm{m}^{-2}\right) r=0.55$ (men), $r=0.55$ (women). C Lean body mass (kg) $r=0.59$ (men), $r=0.51$ (women). All correlation coefficients are highly statistically significant $(p<0.001$ for all)

between 18.3 and $10.7 \mu \mathrm{mol} \cdot \mathrm{min}^{-1} \cdot \mathrm{kg} \quad \mathrm{LBM}^{-1}$ $(p<0.0001$ for all $)$ in a multivariate model no statistically significant interaction was observed between centres and LBM. In addition, in the two centres where LBM was measured with either tritiated water or electrical bioimpedance, the relations between EGO and LBM were similar to those of the whole group (Fig. 3).

When EGO was normalised for LBM, the difference between men and women was cancelled $\left(14.8 \pm 2.7\right.$ vs $14.6 \pm 3.8 \mu \mathrm{mol} \cdot \mathrm{min}^{-1} \cdot \mathrm{kg} \mathrm{LBM}^{-1}$, respectively, $p=\mathrm{NS}$ ). In univariate analysis, EGO was also positively related to the degree of overweight (BMI) and per cent body fat; these associations were, however, no longer significant when EGO was normalised for LBM (Fig. 4). Similarly, the tendency of EGO to decline with increasing age $(-1.1 \pm$ $0.7 \mu \mathrm{mol} \cdot \mathrm{min}^{-1}$ per year, $\left.p=0.10\right)$ was lost when ad- 


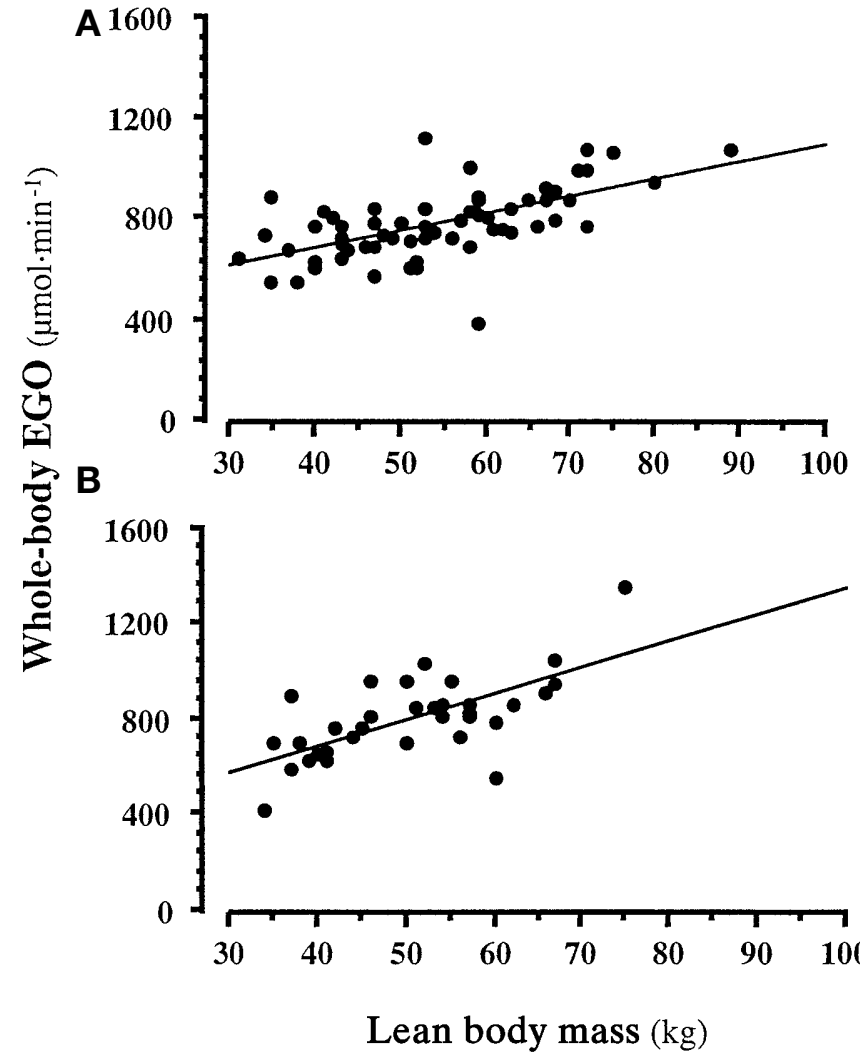

Fig.3 A, B. Scatterplot of whole-body endogenous glucose output (EGO) and lean body mass as measured by bioimpedance $(\mathbf{A}, r=0.61, p<0.0001)$ and tritiated water dilution $(\mathbf{B}$ $r=0.68, p<0.0001)$

Fig. 4A-D. Scatterplots of two indices of body fatness $(\mathbf{A}, \mathbf{B}$, body mass index, BMI; C, D, body fat per cent, FAT) and two way of expressing endogenous glucose output (EGO) (A, C, whole-body EGO; B, D, normalised per lean body mass, LBM-EGO). Male $(\boldsymbol{O})$ and female $(\bigcirc)$ regression lines are indicated by continuous and dotted lines respectively. Correlation coefficients for males and females in $\mathbf{A}$ were $0.26,0.41$ and in $\mathbf{B} 0.22$ and 0.32 , respectively justing for $\mathrm{LBM} \quad\left(0.002 \pm 0.01 \mu \mathrm{mol} \cdot \mathrm{min}^{-1} \cdot \mathrm{kg}\right.$ $\mathrm{LBM}^{-1}$ per year, $p=0.89$ ).

Among the metabolic variables, plasma glucose concentration was directly associated with wholebody EGO; the predicted effect (i.e. the slope of the regression line) was, however, relatively small $\left(77 \pm 22 \mu \mathrm{mol} \cdot \mathrm{min}^{-1}\right.$ per $\mathrm{mmol} / \mathrm{l}$ of plasma glucose $)$ and became statistically not different from zero when EGO was normalised per $\mathrm{kg}$ of LBM $\left(0.70 \pm 0.36 \mu \mathrm{mol} \cdot \mathrm{min}^{-1} \mathrm{~kg} \mathrm{LBM}^{-1}\right.$ per $\mathrm{mmol} / \mathrm{l}$ of plasma glucose, $p=0.06$ ) (Fig. 5). Fasting plasma insulin concentrations (FPI) and insulin sensitivity (IS) were inversely related to one another $(r=0.41$, $p<0.0001)$. Both IS and FPI were inversely related to EGO in an independent fashion (with partial $r$ of 0.19 and 0.21 , respectively, after adjusting for LBM and centre, $p<0.0001$ for both). The predicted independent effects of different FPI or different degrees of peripheral insulin sensitivity on EGO are depicted in Figure 6. Together, LBM, fasting plasma insulin and insulin sensitivity explained $49 \%$ of EGO variability (Fig. 6).

In a subgroup of 223 subjects, the respiratory quotient, measured in the postabsorptive condition, averaged $0.81 \pm 0.05$ (range 0.68-0.97). In this subgroup, EGO was positively related to the respiratory quotient also when EGO was normalised per $\mathrm{kg}$ of LBM (Fig. $7 \mathrm{~A})$; this association remained statistically significant also after adjusting for plasma insulin concentration and insulin sensitivity (partial $r=0.18$, $p<0.01$ ). Plasma NEFA levels, measured in a subgroup of 245 subjects, averaged $0.576 \pm 0.200 \mathrm{mmol} / \mathrm{l}$ (range 0.106-1.353), were inversely related to the respiratory quotient $(r=0.23, \quad p<0.002, \quad n=202$, Fig. 7B) and showed no association with EGO (Fig. 7C).
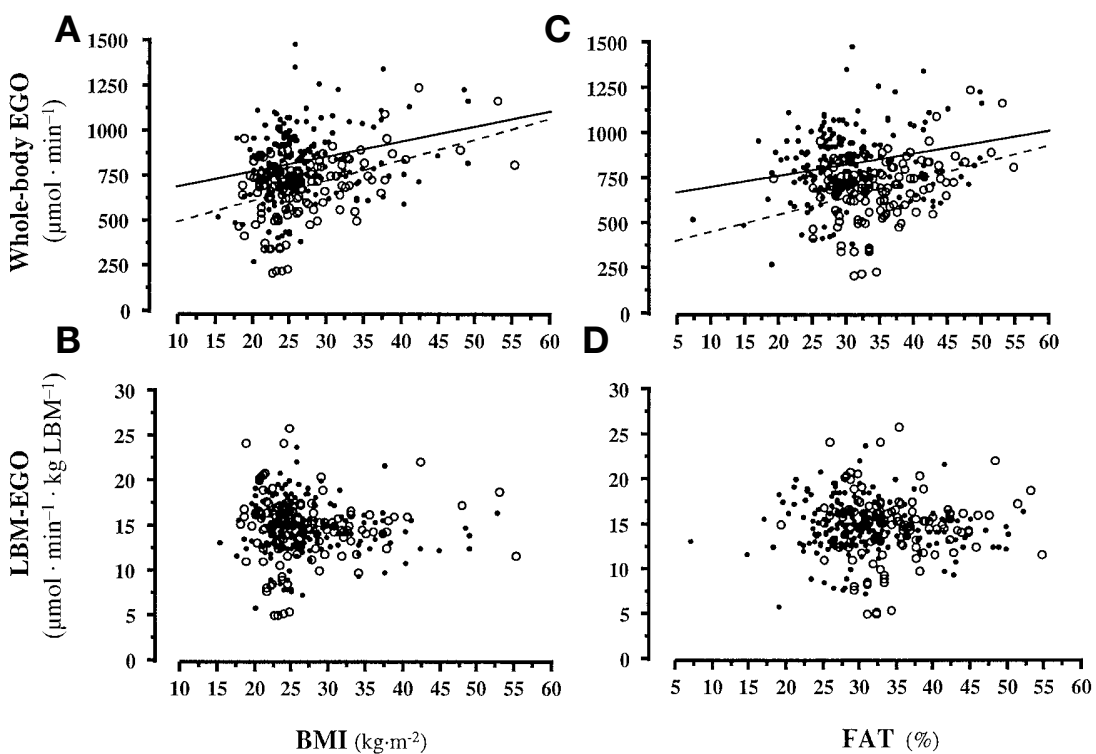

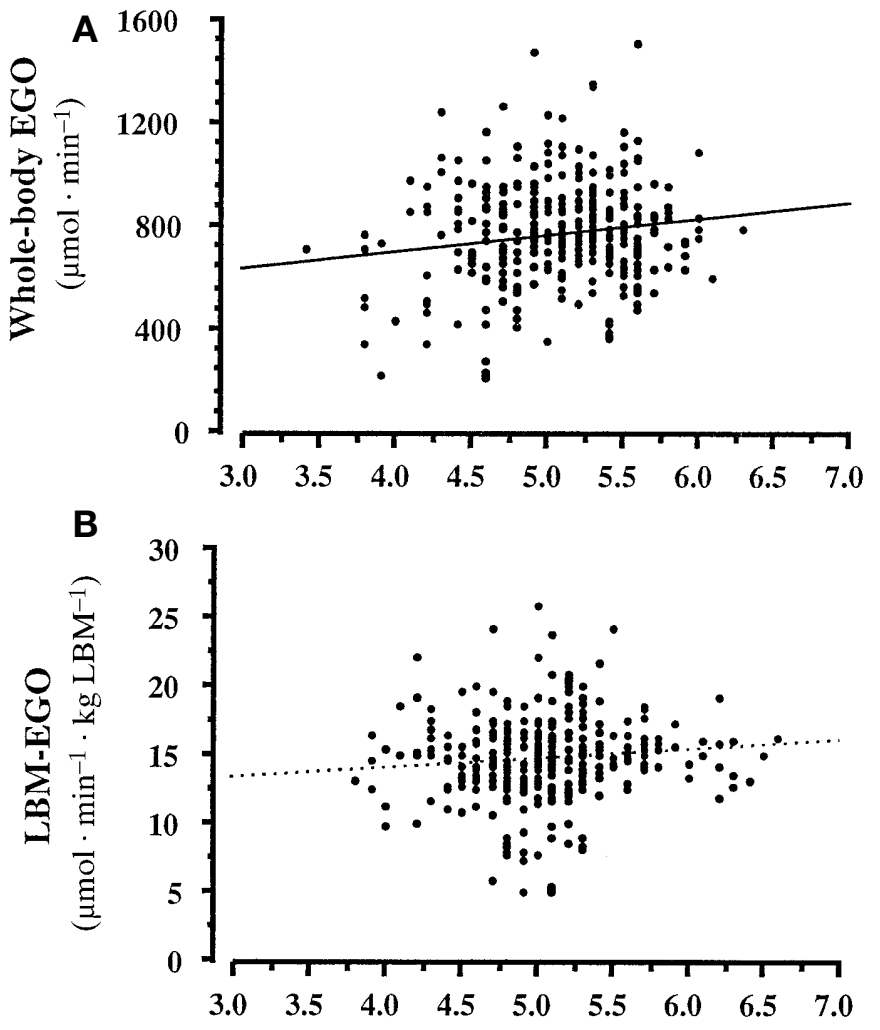

Fasting plasma glucose ( $\mathrm{mmol} / \mathrm{l})$

Fig.5A, B. Scatterplots of fasting plasma glucose and two ways of expressing endogenous glucose output (EGO). (A, whole-body EGO, $r=0.15, p<0.005 ; \mathbf{B}$, normalised per lean body mass, LBM-EGO, $r=0.10, p=0.06$ )

Fig. 6A, B. The two curves depict the relation between peripheral insulin sensitivity (A, partial $r=0.19)$ and fasting plasma insulin ( $\mathbf{B}$, partial $r=0.21$ ) with whole-body endogenous glucose output (EGO) as predicted by a multivariate regression model with EGO as dependent variable and lean body mass, fasting insulin, insulin sensitivity and centres as independent variables. The dotted lines indicate the insulin sensitivity and the fasting plasma insulin values corresponding to an EGO value equal to the mean of the study cohort

\section{Discussion}

Our analysis indicates that in non-diabetic subjects in the postabsorptive condition firstly EGO shows a large variability which mostly reflects the amount of lean mass; the latter fully accounts for the differences in total EGO due to sex, obesity and age. Secondly insulin release (as the peripheral plasma insulin concentration) seems to exert an inhibitory action on EGO. Thirdly a higher EGO is associated with peripheral tissues insulin resistance despite the compensatory hyperinsulinaemia and fourthly a higher EGO is associated with a higher fraction of oxidative metabolism deriving from carbohydrate.

In this large cohort of euglycaemic subjects, total EGO showed a $26 \%$ coefficient of variation $(24 \%$ when normalised for $\mathrm{kg}$ of body weight) and lean mass explained $40 \%$ of this variability. It is possible that the use of Hume's formula to calculate lean body mass introduces some bias in the evaluation of this relation. The observation that Hume's prediction of LBM was highly correlated with direct LBM measurements by tritiated water $(r=0.85)$ or bioimpedance $(r=0.86)$ indicates, however, that any bias, if present, must be small. In addition, both quantitatively and qualitatively the relation between EGO and LBM was similar in men and women, in obese and lean subjects, at each centre and, most importantly, also in the subgroup of subjects in whom LBM was directly measured (by either tritiated water or bioimpedance).

Of note was that the intercept of the regression line of EGO on LBM was not significantly different from zero $\left(-14 \pm 52 \mu \mathrm{mol} \cdot \mathrm{min}^{-1}, p=0.78\right)$, a finding that justifies the LBM normalisation within a wide range of LBM values to be used in case control comparisons. The LBM-independent association of EGO with the respiratory quotient further supports the interpretation that it is the metabolic demand that drives EGO: if the same amount of lean tissue oxidises more glucose for its energetic needs then a larger EGO will be required. The association between EGO and the respiratory quotient was rather weak $(r=0.21)$. It should, however, be considered
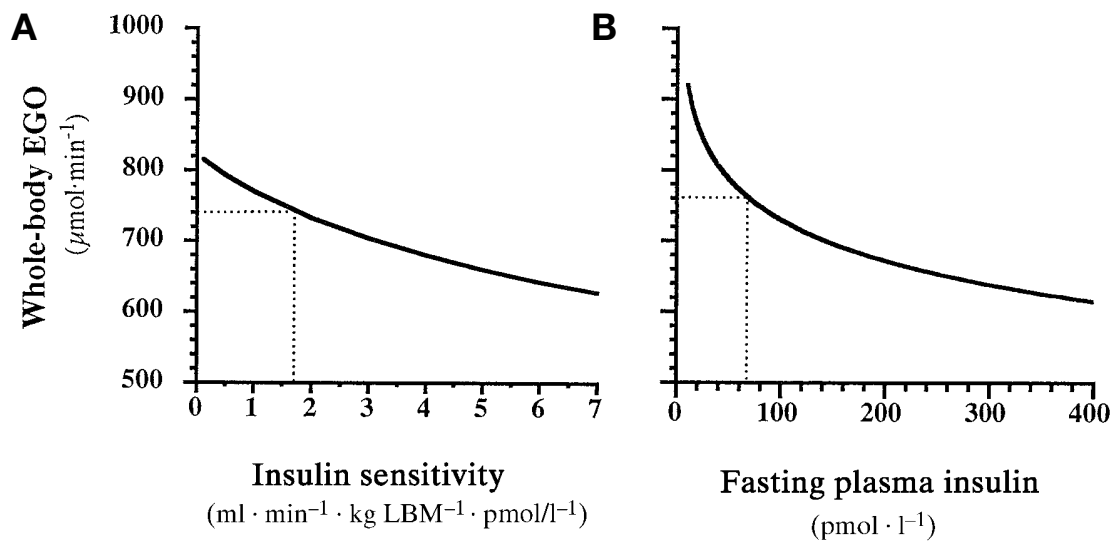

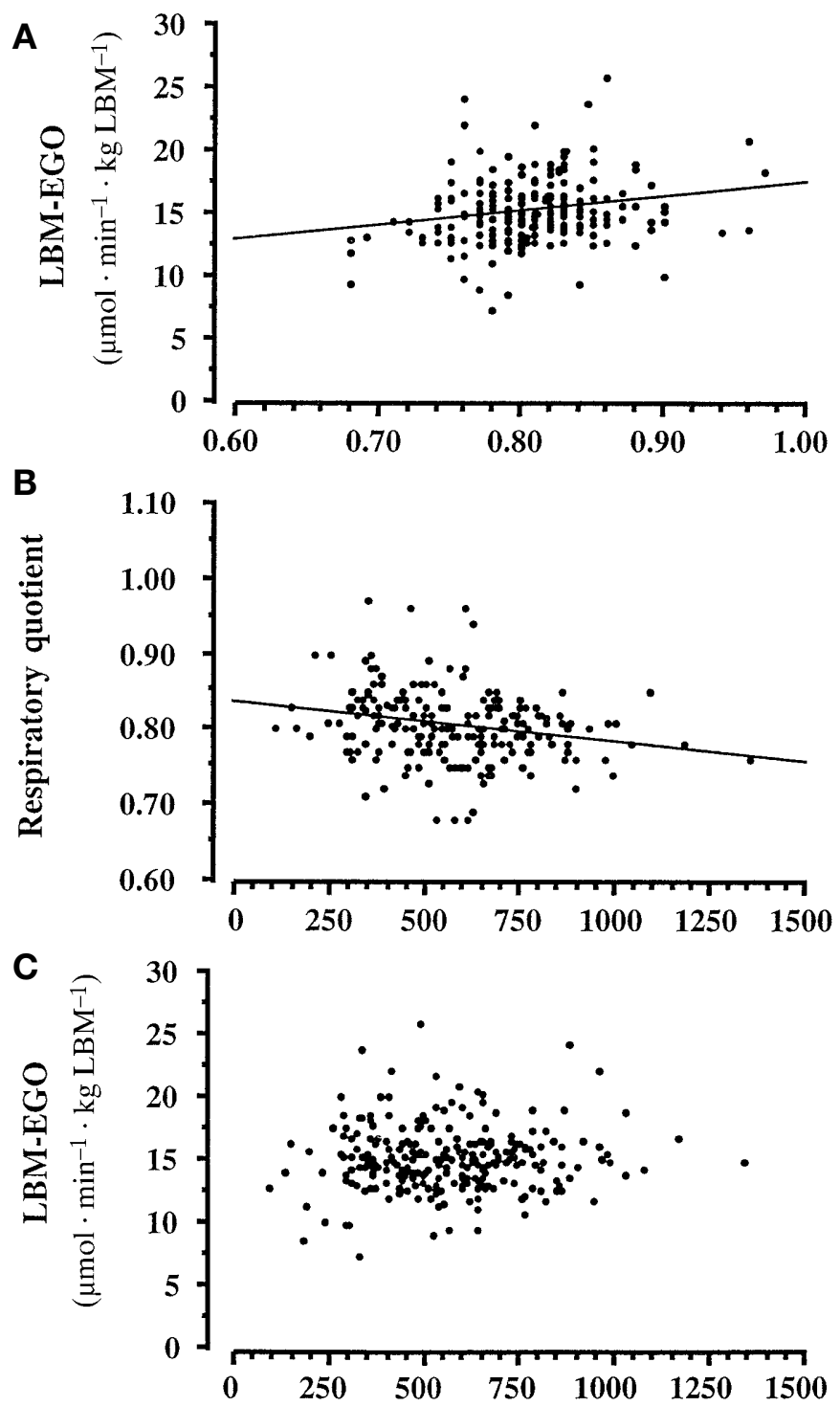

Fig. 7. Scatterplots of endogenous glucose output normalized per kg of LBM (LBM-EGO) and fasting respiratory quotient (A $r=0.21, p<0.002)$, fasting respiratory quotient and fasting plasma non-esterified fatty acids ( $\mu \mathrm{mol} / \mathrm{l})$ (B $r=0.23$, $p<0.002)$, endogenous glucose output normalized per $\mathrm{kg}$ of LBM (LBM-EGO) and fasting plasma non-esterified fatty acids $(\mu \mathrm{mol} / \mathrm{l})(\mathbf{C} r=0.05, p=\mathrm{NS})$

that the measurement of the respiratory quotient is affected by a rather large error (20-25\%), that only a fraction of basal glucose disposal is oxidised (an average of $50 \pm 35 \%$ in the data set in our study) and finally that only a portion of the oxidised carbohydrate is glucose taken up from the plasma (the other source being glycogen).

As expected [12], FPI and peripheral insulin sensitivity were inversely related to one another, the actual relation being better described by a hyperbolic function. Of note is that the variability explained by this relation was quite small $(15 \%)$ and roughly half that previously reported to exist between FPI and the $M$ value [8]. Also in our dataset FPI and M had, however, a correlation coefficient of 0.57 . The apparent discrepancy stems from IS being here calculated as the insulin-stimulated glucose clearance normalised by the clamp-induced rise in plasma insulin concentration. This index is formally a more correct estimate of peripheral tissues insulin sensitivity as it represents the slope of the insulin dose-response function and is independent of basal glucose clearance. It is of note that, notwithstanding their inverse association, FPI and insulin sensitivity showed an independent (and qualitatively similar) influence on EGO when analysed by multivariate regression. Quantitatively (i.e. regression and correlation coefficients), the effect of plasma insulin concentration and peripheral insulin resistance on EGO were small. The mean of the cohort falls, however, into the steep portion of the respective curves, indicating that these two factors are effective to the maximum in a large segment of the study subjects. Although peripheral plasma insulin concentrations are a poor index of portal insulin concentrations, the negative relation between FPI and EGO does suggest an inhibitory action of insulin on EGO. This finding is obviously compatible with the known physiological actions of insulin to restrain free glucose formation through the inhibition of glycogenolysis and glucose-6-phosphatase activity [13]. The negative relation between EGO and peripheral insulin sensitivity is, however, of major physiological interest: independently of plasma insulin concentrations, insulin-resistant subjects have relatively higher rates of EGO. Descriptively, this result indicates that the presence of resistance to insulin of glucose uptake in peripheral tissues is coupled to the reduced ability of insulin to restrain EGO. Whether the cellular basis (insulin binding or intracellular signalling or both) is the same at the two sites or whether peripheral insulin resistance is associated with higher EGO through different mechanisms (e.g. relative hyperglucagonaemia, higher substrate pressure, etc.) cannot be decided by these data. With regard to the latter possibility, we analysed plasma non-esterified fatty acid concentrations (available in a subset of 232 subjects) which, as suggested by studies both in animals [14] and humans [15], appear to exert an important modulatory action on EGO, at least in the short-term. In our study cohort, neither at baseline nor during the last $40 \mathrm{~min}$ of the clamp was there any statistically significant correlation of plasma NEFA concentration with EGO. The possibility remains, that circulating concentrations of gluconeogenic substrates or counter-regulatory hormones are more increased in insulin-resistant than in insulin-sensitive subjects.

Acknowledgements. On behalf of EGIR, we wish to thank Groupe Lipha, in the person of Dr. C. Hubert for their generous support of the activities of the Group. Members of the European Group for the Study of Insulin Resistance (EGIR): 
Table 1. Study cohort characteristics

\begin{tabular}{|c|c|c|c|}
\hline & Mean \pm SD & Range & Median [IQR] \\
\hline Age (yrs) & $43 \pm 15$ & $18-85$ & $41[23]$ \\
\hline Weight (kg) & $77 \pm 18$ & $40-180$ & $75[20]$ \\
\hline $\operatorname{BMI}\left(\mathrm{kg} \times \mathrm{m}^{-1}\right)$ & $26.6 \pm 6.0$ & $15.4-55.1$ & $25.0[5.4]$ \\
\hline FAT $(\%)$ & $32 \pm 7$ & $7-55$ & $31[8]$ \\
\hline $\mathrm{f}-\mathrm{PG}\left(\mathrm{mmol} \times \mathrm{l}^{-1}\right)$ & $5.05 \pm 0.47$ & $3.80-6.60$ & $5.00[0.50]$ \\
\hline $\mathrm{f}-\mathrm{PI}\left(\mathrm{pmol} \times \mathrm{l}^{-1}\right)$ & $71 \pm 39$ & $10-412$ & $66[38]$ \\
\hline ss-PG $\left(\mathrm{mmol} \times \mathrm{l}^{-1}\right)$ & $5.07 \pm 0.48$ & $3.40-6.30$ & $5.10[0.70]$ \\
\hline ss-PI $\left(\mathrm{pmol} \times \mathrm{l}^{-1}\right)$ & $510 \pm 148$ & $226-1198$ & $491[180]$ \\
\hline ss-EGO $\left(\mu \mathrm{mol} \times \min ^{-1} \times \mathrm{kg} \mathrm{LBM}^{-1}\right)$ & $-0.6 \pm 6.2$ & $-30.1-13.3$ & $0[2.0]$ \\
\hline $\mathrm{M}\left(\mu \mathrm{mol} \times \mathrm{min}^{-1} \times \mathrm{kg} \mathrm{LBM}^{-1}\right)$ & $47 \pm 15$ & $15-106$ & $45[20]$ \\
\hline ss-GCL $\left(\mathrm{ml} \times \min ^{-1} \times \mathrm{kg} \mathrm{LBM}^{-1}\right)$ & $9.2 \pm 3.0$ & $2.8-23.8$ & $8.9[4.1]$ \\
\hline IS $\left(\mathrm{ml} \times \mathrm{min}^{-1} \times \mathrm{kg} \mathrm{LBM}^{-1} \times \mathrm{pmol} / \mathrm{l}^{-1}\right)$ & $1.61 \pm 1.00$ & $-0.25-5.83$ & $1.42[1.22]$ \\
\hline
\end{tabular}

FAT $=$ per cent body fat; f-PG = fasting plasma glucose; $\mathrm{f}-\mathrm{PI}=$ fasting plasma insulin; $\mathrm{f}-\mathrm{EGO}=$ fasting endogenous glucose output; $\mathrm{f}-\mathrm{GCL}=$ fasting plasma glucose clearance; ss$\mathrm{PG}=$ steady-state (clamp) plasma glucose; ss-PI = steady-state

H. Beck-Nielsen (University of Odense, Denmark), P. Bell (University of Belfast, UK), E. Bonora (University of Verona, Italy), B. Capaldo (Federico II University, Naples, Italy), P. Cavallo-Perin (University of Turin, Italy), S. Del Prato (University of Padova, Italy), E. Ferrannini (CNR Institute of Clinical Physiology, Pisa, Italy), D. Fliser (University of Heidelberg, Germany), A. Golay (University of Geneva, Switzerland), L. C. Groop (Lund University, Sweden), S. Jacob (Stadtklinik, Baden-Baden, Germany), M. Laakso (University of Kuopio, Finland), N. Lalic (University of Belgrade, Yugoslavia), G. Mingrone (Catholic University, Rome, Italy), A. Mitrakou (University of Athens, Greece), G. Paolisso (University of Naples II, Napoli, Italy), K. Rett (University of München, Germany), U. Smith (University of Göteborg, Sweden), M. Weck (Kreischa, Germany), H. Yki-Järvinen (University of Helsinki, Finland).

\section{References}

1. Ferrannini E, Barrett E, Bevilacqua JS, DeFronzo RA (1983) Effects of fatty acids on glucose production and utilization in man. J Clin Invest 72: 1737-1747

2. Jeng C, Sheu W, Fuh M, Chen Y, Reaven G (1994) Relationship between hepatic glucose production and fasting plasma glucose concentration in patients with NIDDM. Diabetes 43: 1440-1444

3. Muller C, Assimacopoulos-Jeannet F, Mossimann F et al. (1997) Endogenous glucose production, gluconeogenesis and liver glycogen concentration in obese non-diabetic patients. Diabetologia 40: 463-468

4. Mevorach M, Giacca A, Aharon Y, Hawkins M, Shamoon H, Rossetti L (1998) Regulation of endogenous glucose production by glucose per se is impaired in type 2 diabetes mellitus. J Clin Invest 102: 744-753 plasma insulin; ss-EGO = steady-state (clamp) endogenous glucose output; ss-GCL = steady-state (clamp) plasma glucose clearance

5. Stumvoll M, Chintalapudi U, Perriello G, Welle S, Gutierrez O, Gherich J (1995) Uptake and release of glucose by the human kidney. J Clin Invest 96: 2528-2533

6. Tappy L (1995) Regulation of hepatic glucose production in healthy subjects and patients with non-insulin-dependent diabetes mellitus. Diabetes Metab 21: 233-240

7. Brandi LS, Santoro D, Natali A et al. (1993) Insulin resistance of stress: sites and mechanisms. Clin Sci (Colch) 85: 525-535

8. Ferrannini E, Natali A, Bell P, Cavallo-Perin P, Lalic N, Mingrone G (1997) Insulin resistance and hypersecretion in obesity. J Clin Invest 100: 1166-1173

9. Hume R (1966) Prediction of lean body mass from height and weight. J Clin Pathol 19: 389-391

10. DeFronzo RA, Tobin JD, Andres R (1979) Glucose clamp techique: a method for quantifying insulin secretion and resistance. Am J Physiol 237: E214-E223

11. Camastra S, Bonora E, DelPrato S, Rett K, Weck M, Ferrannini E (1999) Effect of obesity and insulin resistance on resting and glucose-induced thermogenesis in man. Int $\mathbf{J}$ Obes 23: 1307-1313

12. Kahn S, Prigeon R, Mcculloch D et al. (1993) Quantification of the relationship between insulin sensitivity and beta-cell function in human subjects. Evidence for a hyperbolic function. Diabetes 42: 1663-1672

13. Petersen K, Laurent D, Rothman D, Cline G, Shulman G (1998) Mechanism by which glucose and insulin inhibit net hepatic glycogenolysis in humans. J Clin Invest 101: 1203-1209

14. Rebrin K, Steil G, Getty L, Bergman R (1995) Free fatty acid as a link in the regulation of hepatic glucose oputput by peripheral insulin. Diabetes 44: 1038-1045

15. Chen X, Iqbal N, Boden G (1999) The effects of free fatty acids on gluconeogenesis and glycogenolysis in normal subjects. J Clin Invest 103: 365-732 